\title{
Predictors of Psychological Well-Being among Higher Education Students
}

\author{
Thomas Harding ${ }^{1}$, Violeta Lopez ${ }^{2}$, Piyanee Klainin-Yobas ${ }^{2 *}$ \\ ${ }^{1}$ School of Health Sciences, College of Education, Health and Human Development, University of Canterbury, \\ Christchurch, New Zealand \\ ${ }^{2}$ Alice Lee Centre for Nursing Studies, Clinical Research Centre, National University of Singapore, \\ Singapore City, Singapore \\ Email: thomassharding@gmail.com, ^nurvl@nu s.edu.sg
}

How to cite this paper: Harding, T., Lopez, V., \& Klainin-Yobas, P. (2019). Predictors of Psychological Well-Being among Higher Education Students. Psychology, 10, 578-594.

https://doi.org/10.4236/psych.2019.104037

Received: February 11, 2019

Accepted: March 17, 2019

Published: March 20, 2019

Copyright $\odot 2019$ by author(s) and Scientific Research Publishing Inc. This work is licensed under the Creative Commons Attribution International License (CC BY 4.0).

http://creativecommons.org/licenses/by/4.0/

\begin{abstract}
This study aimed to examine the relationships among stress, protective factors and psychological well-being (PWB). A cross-sectional predictive research design was carried out. A convenience sample of 152 students was recruited from a higher education institution in New Zealand. Data were collected by using online self-reported questionnaires and analysed by descriptive statistics and path analyses (with IBM AMOS). Results showed that the hypothesised model fit well with the sample data. Resilience, mindfulness, support from family, and support from significant others were significant predictors of PWB. Furthermore, stress significantly predicted social support, resilience, self-efficacy, and mindfulness. There is the need to develop prevention interventions (e.g., a resilience-building and mindfulness interventions) for students to help them manage stress and achieve PWB.
\end{abstract}

\section{Keywords}

Mindfulness, Psychological Well-Being, Resilience, Social Support, Stress

\section{Introduction}

The positive psychology theory emphasises strengthening individuals' positive experiences, positive personality traits and positive community/institutions to achieve well-being (Seligman \& Csikszentmihalyi, 2000). Within this framework, healthcare providers are required to comprehend the concept of positive psychology and to provide health promotion inventions for people in hospitals and community settings. Psychological well-being (PWB) is one of the important in- 
dicators of positive psychology that warrants further investigations. Two philosophical foundations of PWB are known as Hedonism and Eudaimonia (Vazquez, Hervas, Rahona, \& Gomez, 2009). The Hedonic philosophy has its goals to build individuals' life with a substantial amount of positive affects (such as happiness, enjoyment, and satisfaction) and to minimise negative affects (Ryan \& Deci, 2001). The Eudaimonic philosophy focuses on living life the fullest potential and on achieving self-actualisation (Ryan \& Deci, 2001). Eudaimonic PWB are described as autonomy, self-acceptance, personal growth, purpose in life, positive relations with others, and environmental mastery (Ryff \& Keyes, 1995).

Students in Higher Educations worldwide encounter many factors that might affect their PWB. In USA, stress (as measured by the student stress survey and minority status stress scale) negatively impacted PWB among students at two public universities (Crudup, 2013). Furthermore, American first-year college students who were female, Latino/Hispatic, and older than traditional age; and those with high academic achievement were more likely to report greater PWB (Bowman, 2010). In comparison with PWB scores before entering the university, students who had positive interactions with diverse students gain higher PWB at the end of first year (Bowman, 2010). In the United Kingdom, university students experienced multiple challenges such as academic and financial pressures (Cooke, Bewick, Barkham, Bradley, \& Audin, 2006). A longitudinal study of first-year students $(\mathrm{n}>2000)$ revealed that PWB declined across time (Cooke et al., 2006). Specifically, PWB scores at the end of semester one and semester two were significantly lower than that at the baseline (before commencing the study) (Cooke et al., 2006). Conversely, a cross-sectional study examined students' PWB at a church-affiliated university in Tanzania. Results showed that higher percentage of third-year students (80.7\%) felt themselves as flourishing (a component of PWB) than those of first-year (70.6\%) and second-year students (68.3\%). The conflicting findings above might suggest that PWB levels varied across settings; therefore, there is a need to explore students' PWB across settings and countries.

In New Zealand, the last decade has seen considerable research focus in higher education on the pressures faced by international students; and the issues with respect to retention and completion for Mãori (the indigenous people) and $\mathrm{Pa}$ cific Island students. There has been little research to date on PWB levels in university settings. However, there is some evidence that students in higher education in New Zealand experienced stress from academic and financial pressures (Manthei \& Gilmore, 2005) and that the stressors they encountered could contribute to psychological disorders (Kypri, Langley, McGee, Saunders, \& Williams, 2002; Samaranayake \& Fernando, 2011; Samaranayake, Arroll, \& Fernando, 2014).

\subsection{The Psychological Well-Being (PWB) Promotion Model}

In this study, we utilised the PWB promotion model, developed according to the 
Neuman's system theory (Neuman \& Fawcett, 2002) and Eudaimonic PWB (Ryff \& Keyes, 1995). Figure 1 shows four main constructs: Stress, Resource protection factors, Psychological well-being, and Prevention intervention. Stress refers to a state of biopsychological changes (such as hyperventilation, hypertension and the feeling of nervousness) in response to undesirable situations. Evidence shows that stress is prevalent among students in many countries such as Canada (Adlaf, Gliksman, Demers, \& Newtown-Taylor, 2001), Sweden (Vaez, Kristenson, \& Laflamme, 2004), United Kingdom (Denovan \& Macaskill, 2013), USA (Blanco, Okuda, Wright, Hasin, Grant, Liu, \& Wolfson, 2008) and New Zealand (Manthei \& Gilmore, 2005). Within the model, it is postulated that stress has both direct and indirect effects (through resource protection factors) on PWB.

Neuman \& Fawcett (2002) defined health as the state of wellness/equilibrium where individuals' components (physiological, psychological, sociocultural, spiritual, and developmental ones) function in harmony. Following this conceptualisation, PWB then refers to individuals' best possible psychological state at any given time. This study examined the Eudaimonic PWB which emphasises living well with the fullest potential (Ryff \& Keyes, 1995).

Resource protection factors (RPF) are defined as individuals' factors that are activated following the invasion of stressors with the goals to protect the individuals from the adverse effects of stress (Neuman \& Fawcett, 2002). RPF comprises internal factors (such as resilience, self-efficacy, and mindfulness) and external factors (such as social support). Existing studies revealed that PWB is linked to resilience (Daud, Klinteberg, \& Rydelius, 2008; Fava \& Tomba, 2009), self-efficacy (Priesack \& Alcock, 2015; Salami, 2010; Tamannaeifar \& Motaghedifard, 2014), mindfulness (Barbosa, Raymond, Zlotnick, Wilk, Toomey, \& Mitchell, 2013; Bowlin \& Baer, 2012; Keng, Smoski, \& Robins, 2011), and social support (Rueger, Malecki, \& Demaray, 2010; Seeds, Harkness, \& Quilty, 2010).

Prevention intervention helps individuals achieve the state of psychological well-being. The intervention encompasses three levels: primary (promoting health and preventing stress among healthy individuals); secondary (restoring health among people who suffer from stress-related symptoms); and tertiary (regaining and maintaining normal functioning). The prevention intervention may aim to strengthen individuals' RPF, including resilience, self-efficacy, mindfulness, social support, among others. Results from this may help pave the way to develop preventions for student in higher education.

\subsection{The Current Study}

Limited studies have examined the simultaneous effect of stress, internal RPF and external RPF on psychological well-being among higher education students, suggesting gaps in the existing literature. Such knowledge is imperative for the development of prevention interventions for the young population in the near future. Guided by the PWB promotion model (Figure 1) and previous empirical evidence, we formulated the following hypotheses: 


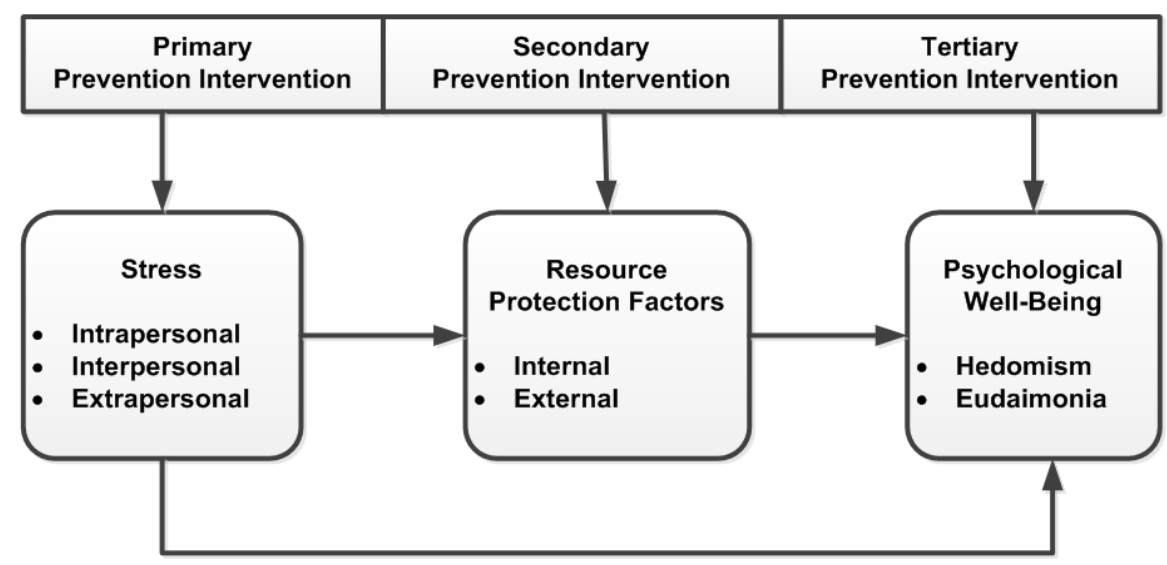

Figure 1. The psychological well-being promotion model. Note: The model was developed based on the Neuman's system theory (Neuman, 2002) and Eudaimonic psychological well-being theory (Ryff \& Keyes, 1995).

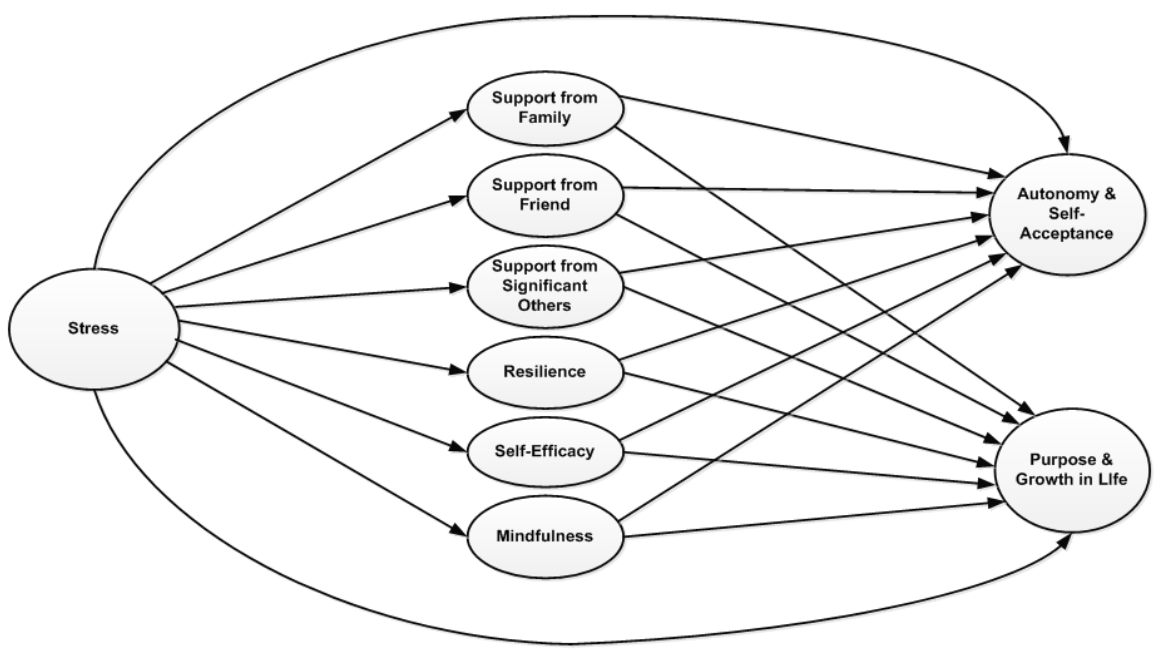

Figure 2. The hypothesised model.

1) Internal RPF, including mindfulness, resilience, and self-efficacy, would have positive impact on PWB among higher education students in New Zealand.

2) External RPF, social support, would have a positive effect on the students' PWB.

3) Stress would have the adverse effects on internal RPF, external RF, and PWB among the students.

\section{Methods}

\subsection{Research Design}

A cross-sectional descriptive predictive design was used to examine the effects of independent variables on dependent variables in a naturally-occurring setting (Grove, Burns, \& Gray, 2013). The hypothesised model is displayed in Figure 2, where all ellipses represent study variables and arrows mean hypothesised relationships (regression paths) among variables. We performed primary analyses of 
study variables by running exploratory and confirmatory factor analyses to examine the factor structures of each measurement. As a result, stress, resilience, self-efficacy and mindfulness showed one factor. PWB had a two-factor solution, including Autonomy and Self-acceptance, and Purpose and Growth in Life. Moreover, social support displayed three factors: Support from family; Support from friend; and Support from significant others. Note that the detailed results of factor analyse are not shown in this paper.

\subsection{Participants}

Potential participants were recruited from a higher education institution in New Zealand via convenience sampling. Eligibility criteria included being students who were enrolled in undergraduate degrees at the institution and having no severe medical or mental health problems that require hospitalization during the period of recruitment. We excluded such students because severe health problems might contribute to higher levels of stress related to discomfort, treatments, and financial situations, among others. Such factors might affect students' psychological well-being and thus confound the research findings.

The project commenced following the approval of the Institutional Review Board and data collection began on 1 September 2015 till 31 August 2016. The researchers explained the purpose of the study and distributed participant information sheet (PIS) to eligible students. Those who interested were given a link to online anonymous questionnaire via e-mails and were asked to complete the questionnaire. It was emphasised that participation in this study would be voluntary and there would be no penalty on the students' decision to take or not to partake in this study.

To determine sample size for this study, we used a formulae for testing multiple relationships $\mathrm{N}>50+8 \mathrm{~m}$, where $\mathrm{m}$ is the number of independent variables (Green, 1991). Given seven independent variables in this study, an adequate sample size should be more than 116 students [ $50+(8 \times 7)]$. To enhance generalisability of research findings, we took all eligible students who completed the online questionnaires as a final sample.

\subsection{Settings}

The study was undertaken at a medium size regional institution of higher education in New Zealand which offers a range of qualifications from vocational diplomas through to baccalaureate and masters' degrees. The target population was all the students enrolled in undergraduate degrees across all Faculties: a total of 1176 students.

\subsection{Measurement}

PWB reflects positive mental health and positive functioning, which was measured by the PWB scale (Ryff \& Keyes, 1995). The scale comprises 18 items, each item has six categories ranging from 1 (strongly disagree) to 6 (strongly agree). 
We did a series of exploratory and confirmatory factor analyses of the scale and the findings suggested the two factor solutions: Autonomy/Self-Acceptance (AS, 10 items) and Purpose/Growth in Life (PG, 5 items). Five items were excluded from further analyses due to low factor loadings $(\lambda<0.30)$. Possible scores for the AS factor are $10-60$ and for the PG factor are 5 - 30 with higher scores signifying higher levels of PWB. In our study, reliability of the PWB appeared with Cronbach's alpha of 0.82 and 0.63 for the AS and PF factor respectively (Table 1).

Stress was assessed with the 10-item perceived stress scale (PSS. Cohen, Kamarck, \& Mermelstein, 1983), asking respondents the perception of their stressful situations in the past month. The PSS was developed to use for community participants, which fit well with our sample (students in higher education). All items are scored from 1 (Never) to 5 (Very Often) and the total scores range from 10 to 50 with higher scores suggesting higher levels of stress. In this study, factor analyses showed that the PSS displayed a one-factor solution and this evidence supported its construct validity. Furthermore, the PSS Cronbach's alpha was 0.92 for the current sample, suggesting excellent internal consistency reliability.

Mindfulness refers to the state that individuals are attentive to and aware of a current situation with a non-judgmental attitude (Kabat-Zinn, 1990). The 15-item mindful attention awareness scale (MAAS; Brown \& Ryan, 2003) was devised to capture dispositional mindfulness. The MAAS items are scored from 1 (almost always) to 6 (almost never) making up the total score of 15 - 90. Higher scores suggests higher levels of mindfulness. In this study, the construct validity of the MAAS was supported by the one-factor structure (findings from factor analyses). The current sample showed Cronbach's alpha of 0.91, suggesting excellent reliability.

Resilience refers to persons' ability to cope effectively even in the face of adversity, suggesting positive adaptation (Wagnild, 2009). Resilience is regarded as a protective factor against stressful situations and mental health problems (Wagnild, 2009). The original Connor-Davidson Resilience scale (CD-RISC; Connor \& Davidson, 2013) has 25 items. Later, the 10-items CD-RISC was established according to results from further factor analyses (Campbell-Sills \& Stein, 2007). The 10-item CD-RISC comprises five response options from 1 (Not true at all) to 5 (True nearly all the time) with the total scores of 1 - 50. Highest scores signify highest level of resilience. For the current sample, the CD-RISC displayed one-factor structure with excellent reliability (Cronbach's alpha of $0.91)$.

Self-efficacy refers to individuals' self-evaluation of their capability to perform certain tasks in order to accomplish beneficial outcomes (Bandura, 1977). The Generalized self-efficacy scale (GSC; Schwarzer \& Jerusalem, 1995) has been used worldwide to capture self-efficacy in various populations. The GSC has 10 items and each item is scored on four-response options from 1 (Not at all true) to 4 (Exactly true). The composite scores are in the range of $10-40$ with the 
Table 1. Descriptive information of study variables $(n=152)$.

\begin{tabular}{|c|c|c|c|c|c|c|c|}
\hline Variables & Mean & $\begin{array}{l}\text { Standard } \\
\text { deviation }\end{array}$ & Skewness & Kurtosis & Possible scores & Actual scores & $\begin{array}{c}\text { Cronbach's } \\
\text { alpha }\end{array}$ \\
\hline \multicolumn{8}{|l|}{ Psychological Well-being } \\
\hline Mastery \& self-acceptance & 43.03 & 8.38 & -0.47 & -0.31 & $10-60$ & 2160 & 0.82 \\
\hline Purpose \& growth in life & 24.93 & 3.87 & -0.96 & 0.68 & $5-30$ & $13-30$ & 0.63 \\
\hline Stress & 29.05 & 8.47 & 0.08 & -0.611 & $10-50$ & $10-50$ & 0.92 \\
\hline Support from family & 21.32 & 6.11 & -1.03 & 0.49 & $4-28$ & $4-28$ & 0.93 \\
\hline Support from friend & 21.26 & 5.35 & -1.01 & 0.91 & $4-28$ & $4-28$ & 0.93 \\
\hline Support from significant others & 21.74 & 6.91 & -1.15 & 0.32 & $4-28$ & $4-28$ & 0.95 \\
\hline Resilience & 38.36 & 7.38 & -0.58 & 0.20 & $10-50$ & $16-50$ & 0.91 \\
\hline Self-Efficacy & 31.20 & 4.46 & -0.33 & 0.40 & $10-40$ & $16-40$ & 0.88 \\
\hline Mindfulness & 57.47 & 14.28 & -0.23 & -0.34 & $15-90$ & $19-90$ & 0.91 \\
\hline
\end{tabular}

highest score reflecting highest sense of generalised self-efficacy. For the current sample, the GSC displayed one factor with excellent reliability (Cronbach's alpha of 0.88).

Social support is considered a multidimensional construct reflecting the amount of social network, the provisional of support and perceived support adequacy (Canty-Mitchell \& Zimet, 2000). The multidimensional scale of perceived social support (MSPSS, Zimet, Dahlem, Zimet, \& Farley, 1988) was tested on university students, adolescents, and people with mental disorders. The MSPSS comprises 12 items and all items are scored on seven-point Likert-type option from 1 (very strongly disagree) to 7 (very strongly agree). In this study, the scale displayed three distinct factors: support from family (4 items), support from friend (4 items), and support from significant others ( 4 items). Total scores for each factor are in the range of 4 - 20 with the highest scores suggesting the highest perceived social support. For the current sample, Cronbach's alphas were $0.93,0.93$, and 0.95 for support from family, support from friend, and support from significant others respectively.

\subsection{Data Analyses}

Information from the online questionnaires was automatically converted into a SPSS file. Data analyses in this study were divided into three phases. The first phase used IBM SPSS Software version 24 to examine participants' characteristics. Furthermore, study variables (such as PWB, mindfulness, and self-efficacy) were explored using descriptive statistics (such as mean, standard deviation, skewness, and kurtosis). The second phase involved examining internal consistency reliability of each measurement and Cronbach's alphas were reported. The final phase of data analyses aimed to test the study hypotheses. As such, path analyses were performed using IBM AMOS version 23. The hypothesised model was submitted to the AMOS software. 
Path analysis allows the analysis of a more complicated theoretical model with multiple independent and dependent variables (Norman \& Streiner, 2003). Path analysis may be viewed as a series of multiple regressions. To determine if the hypothesised model would be acceptable, we reviewed the following fit indices: 1) $\chi^{2}$ per degree of freedom $\left.\left(\chi^{2} / \mathrm{df}\right)<2 ; 2\right)$ comparative fit index $(\mathrm{CFI})$, incremental fit index (IFI), and Tucker-Lewis index (TLI) $>0.90$ (reasonable fit) and $>0.95$ (good fit); 3) root mean square error of approximation (RMSEA) < 0.05 (good fit), $<0.08$ (adequate fit), and $<0.10$ (marginal fit); and d) narrow $90 \%$ confidence internal around RMSEA (Bryne, 2010; Browne \& Cudeck, 1993; Hu \& Bentler, 1999; Norman \& Streiner, 2003). Additionally, standardised regression coefficients $(\beta)$ and coefficient of determination $\left(R^{2}\right)$ were used to determine the effects of independent variables on dependent ones.

\section{Results}

\subsection{Characteristics of Participants}

A total of 152 completed online self-administered questionnaire were entered to IBM SPSS. An average age of students was 30.10 years $(S D=11.28)($ Table 2$)$. Most of them were female $(87.50 \%, \mathrm{n}=133)$ and had no religion $(57.20 \%, \mathrm{n}=$ 87). Regarding race, the majority were New Zealand European $(61.20 \%, \mathrm{n}=93)$ followed by Māori $(19.70 \%, \mathrm{n}=30)$. Third-year students were the largest group $(34.21 \%, \mathrm{n}=52)$, followed by the second-year $(25.00 \%, \mathrm{n}=38)$ and first-year $(23.03 \%, \mathrm{n}=35)$. More than half of students were very dissatisfied/dissatisfied with their family income $(51.30 \%, \mathrm{n}=78)$ and some were very satisfied/satisfied $(23.70 \%, \mathrm{n}=36)$.

\subsection{Description of Study Variables}

Table 1 displays descriptive statistics (mean, standard deviation, skewness, kurtosis, and Cronbach's alpha) of the study variables. All variables were approximately normally distributed as evidenced by the kurtosis values between -7 and +7 and kurtosis between -2 to +2 (Hair, Black, Babin, \& Anderson, 2010). All variables (except the purpose and growth in life factor) had acceptable internal consistency reliability as evidenced by Cronbach's alpha greater than 0.70 (Bland \& Altman, 1997; DeVellis, 2003).

\subsection{Effects of Independent Variables on PWB}

Figure 3 illustrates findings from the path analysis. The solid lines in Figure 3 denote paths with significant regression coefficients $(\beta)$ whereas broken lines represent non-significant paths. An examination of fit indices suggested that the hypothesised model had an acceptable fit with the sample data $\left(\chi^{2} / \mathrm{df}=1.53\right.$, CFI $=0.93, \mathrm{TLI}=0.90, \mathrm{IFI}=0.93, \mathrm{RMSEA}=0.06$, and $90 \%$ confidence interval $=$ $0.05,0.07)$.

Furthermore, current evidence revealed that stress had significant effects on support from family $(\beta=-0.25, p=0.001)$, support from friend $(\beta=-0.44$, 
Table 2. Demographic information of study participants $(n=152)$.

\begin{tabular}{|c|c|c|}
\hline Variables & $\mathbf{n}$ & $\%$ \\
\hline \multicolumn{3}{|l|}{ Gender } \\
\hline Male & 18 & 11.80 \\
\hline Female & 133 & 87.50 \\
\hline Missing & 1 & 0.70 \\
\hline \multicolumn{3}{|l|}{ Race } \\
\hline European/Pakehar & 93 & 61.20 \\
\hline Mauri & 30 & 19.70 \\
\hline Pacific Island & 6 & 3.90 \\
\hline Others & 23 & 15.20 \\
\hline \multicolumn{3}{|l|}{ Religion } \\
\hline Christianity & 46 & 30.30 \\
\hline No religion & 87 & 57.20 \\
\hline Others & 19 & 12.50 \\
\hline \multicolumn{3}{|l|}{ School Year } \\
\hline Year 1 & 35 & 23.03 \\
\hline Year 2 & 38 & 25.00 \\
\hline Year 3 & 52 & 34.21 \\
\hline Year 4 & 7 & 4.61 \\
\hline Year 5 & 2 & 1.32 \\
\hline Year 6 & 4 & 2.62 \\
\hline Missing & 14 & 9.21 \\
\hline \multicolumn{3}{|c|}{ Satisfaction with family income } \\
\hline Very satisfied & 10 & 6.60 \\
\hline Satisfied & 26 & 17.10 \\
\hline Neutral & 38 & 25.00 \\
\hline Dissatisfied & 46 & 30.30 \\
\hline Very dissatisfied & 32 & 21.00 \\
\hline Age (years) & Mean $=30.10$ & $\mathrm{SD}=11.28$ \\
\hline
\end{tabular}

$p<0.001)$, support from significant others $(\beta=-0.26, p<0.001)$, resilience $(\beta=$ $-0.57, p<0.001)$, self-efficacy $(\beta=-0.51, p<0.001)$, mindfulness $(\beta=-0.50, p<$ $0.001)$, and the autonomy \& self-acceptance factor of PWB $(\beta=-0.41, p<$ $0.001)$. Support from family $(\beta=0.11, p=0.04)$, support from significant others $(\beta=0.13, p=0.03)$, resilience $(\beta=0.38, p<0.001)$, and mindfulness $(\beta=0.14, p$ $=0.009)$ significantly influenced the autonomy \& self-acceptance factor. The value of $\mathrm{R}^{2}$ suggested that a variance of $76.90 \%$ on the autonomy and self-acceptance factor was explained by all the independent variables. 


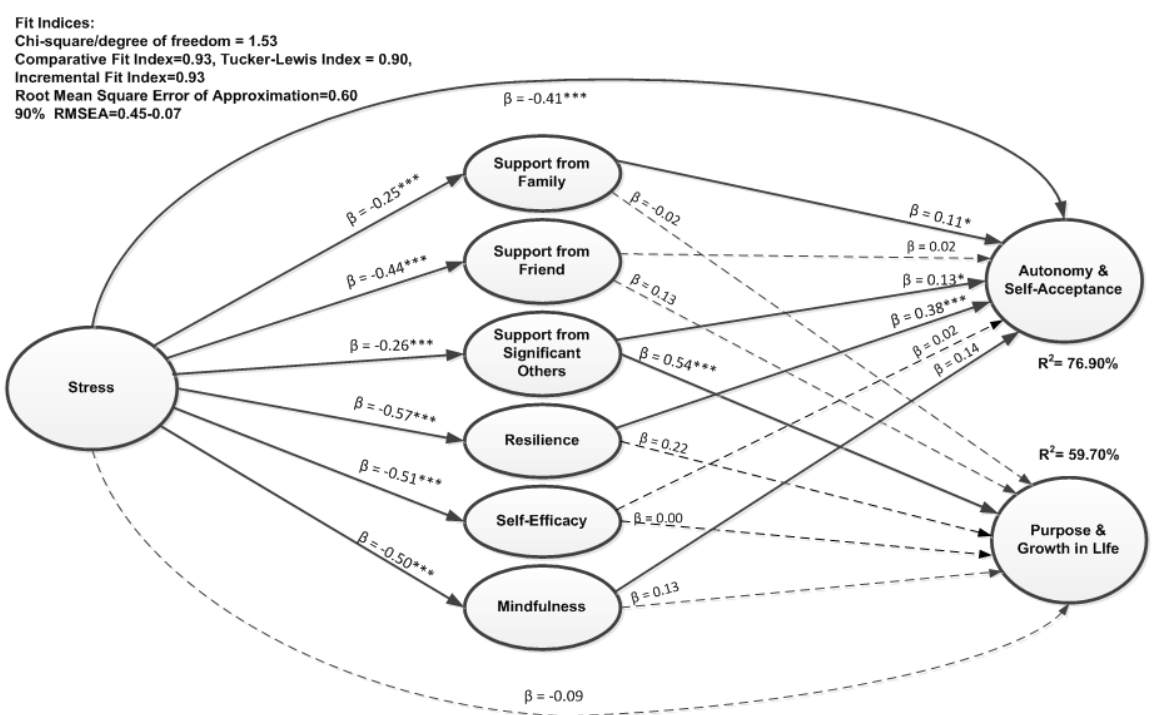

Figure 3. Effects of independent variables on psychological well-being. Note: Solid lines denote paths with significant regression coefficients $(\beta)$, broken lines denote non-significant paths.

In addition, support from significant others $(\beta=0.54, p<0.001)$ had a significant impact on the purpose \& growth in life factor of PWB. A variance of $59.70 \%$ of the PWB factor was explained by all the independent variables.

\section{Discussion}

This study aimed to test the effects of stress, internal RPF and external RPF on PWB among students in higher education in New Zealand. Results from this study revealed that students with higher levels of resilience and mindfulness reported greater levels of the autonomy and self-acceptance, a component of PWB. None of the internal RPF was linked to the purpose and growth in life (another component of PWB). The majority of the students in this study were mature and female; previous studies have postulated that higher levels of resilience occured as a function of age (Feinstein \& Hammond, 2004), and that females scored higher with respect to hardiness commitment (i.e., a focus on turning stressors to advantage) (Sheard, 2009). Additionally, almost $20 \%$ of the participants in this study were Māori and previous research with Māori university students has demonstrated that a strong sense of cultural identity might be an important factor in academic achievement (Bennett, 2002; Tassell, Flett, \& Gavala, 2010). Bennett (2002) suggested that collective self-esteem "moderates the effects of problems on academic achievement" (p. 61). It is possible that a positive cultural identity was associated with resilience.

Previous studies revealed similar findings. Resilience was positively related to indicators of PWB (such as life satisfaction and positive affect) but negatively associated with psychological distress, depression, and anxiety among college students (Beasley, Thompson, \& Davidson, 2003; Mak, Ng, \& Wong, 2011; Nath \& Pradhan, 2012). Resilience is an internal factor enabling students to bounce 
back following stressful situations. It is postulated that resilience is linked with PWB through "positive cognitive triad" (Mak et al., 2011). Specifically, people with high resilience have a positive view about themselves (such as high self-esteem and self-confidence), the world (looking at challenges in undesirable circumstances) and the future (Mak et al., 2011).

Mindfulness plays an important role in positive psychology as it helps enhance PWB. Mindfulness comprises two major components: awareness (a continuous process of monitoring internal and external environments) and attention (a process of focused awareness), which are intertwined with each other (Westen, 1999). Brown and Ryan (2003) reviewed theories and summarised three possible mechanisms of mindfulness on PWB. Firstly, mindful people are able to identify their current needs, values, problems, behaviour, and subjective experiences. Such information is crucial in the process of behavioural changes. Secondly, mindful individuals have the sense of autonomy and they can self-regulate their own behaviour to accomplish their needs (Brown \& Ryan, 2003). Finally, the cautious attention on any activity (such as eating) would enhance the sense of pleasure and vitality on such activity (Brown \& Ryan, 2003). Similar to our findings, a study in the Philippine revealed that mindfulness was a significant predictor of positive PWB and negative PWB among university students (Klainin-Yobas, Ramirez, Fernandez, Sarmiento, Thanoi, Ignacio, \& Lau, 2015). Other research also supported the association between mindfulness and measures of PWB (Barbosa et al., 2013; Bowlin \& Baer, 2012; Keng et al., 2011).

As anticipated, students receiving higher levels of support from family and from significant others were more likely to report greater autonomy and self-acceptance. Support from significant others predicted purpose and growth in life. Similarly, a non-experimental study found that support from family, friends and significant others were associated with positive psychological strengths and subjective well-being among engineering students (Khan \& Husan, 2010). Another qualitative study in Malaysia highlighted the importance of social support on first-year students' well-being (Awang, Kutty, \& Ahmad, 2014). Social interactions within (peer, senior and school support) and outside (family and sibling support) academic environments were of great importance on students' academic, social and emotional adjustment (Awang et al., 2014). Similarly, in New Zealand there is evidence that highlights the importance of both peer and family support (Benseman, Coxon, Anderson, \& Anae, 2006; Glaser, Hall, \& Halperin, 2006). Additionally, for Māori students there is a call for greater action sociopolitically to counter the deficit discourse which has created a potent barrier to educational achievement for minority culture students (Bishop, Berryman, Cavanagh, \& Teddy, 2009). The lack of support through having societal and familial role models is arguably a significant factor for Māori and Pacific Island students. As noted by Benseman, Coxon, Anderson, \& Anae (2006):

"Because of Pasifika under-representation historically in tertiary education, a much higher proportion of students come from families where very few other 
family members have tertiary educational experience. This means that there is less 'cultural capital in these families in terms of accumulated experience and knowledge from which students can draw to help them build academic habits and guide them through the inevitable crises that occur during their studies") (p. 154).

As hypothesised, findings from this study suggested that students who experienced higher levels of stress reported lower levels of all internal RPF (mindfulness, resilience, and self-efficacy), lower external RPF (support from family, support from friend, and support from significant others), and poorer psychological well-being (the autonomy \& self-acceptance component). Similarly, a previous study reported that stress was negatively associated with mental well-being among university students in Singapore (Teh, Archer, Chang, \& Chen, 2013). Furthermore, mental well-being appeared to mediate the adverse effect of stress on perceived health (Teh et al., 2013). Another study also found the link between perceived stress and poorer psychological welling among university students in China (Zhong, 2009).

\section{Strengths and Limitations}

This study was strengthen by the use of two well-established theories to guide hypothesized relationships among study variables. Furthermore, path analyses added more strength by allowing simultaneous tests of multiple independent and multiple dependent variables. Nevertheless, some methodological limitations existed. First, the use cross-sectional research design might hamper an ability to draw conclusion about cause-and-effect among study variables. Secondly, small sample size and single-site recruitment might limit generalisability of research findings. Finally, stress was measured only by a subjective measure (self-reported questionnaire). As such, objective data was not collected.

\section{Conclusion and Future Directions}

This study provided some evidence to partially support the psychological wellbeing promotion model (Figure 1). Specifically, our findings showed that stress significantly influenced internal RPF (resilience, self-efficacy, and mindfulness), external RPF (support from family, support from friend, and support from significant others), and PWB (Autonomy \& Self-acceptance). Note that the magnitude of the relationships between stress and internal RPF were stronger than those with external factors, most of internal RPF (except self-efficacy) and external RPF (except support from friend) significantly affected the autonomy and self-acceptance component. However, only support from significant others significantly influenced the purpose and growth in life component of PWB. Three possible explanations could be provided here. First, such findings may reflect the true phenomena of interest whereby there were no associations among the variables. Therefore, there is a need review the existing literature to identify other internal RPF or external RPF variables. Secondly, the relationships among study 
variables might not be simply linear. Hence, future studies may test the mediating and/or moderating effect of the internal and external RPF variables. Finally, the current findings might be culture- or setting-specific. Accordingly, it is essential to collect data for other settings or countries to compare with our findings.

Students in higher educations encountered various challenges, which may negatively influence their PWB. Given these students are future national workers; it is of great importance to ensure that they maintain good health and psychological well-being. Accordingly to the psychological well-being promotion models (Figure 1), primary, secondary and tertiary prevention interventions are pivotal. As the primary prevention level, stress management programmes could be offered to higher education students. Various stress management strategies included cognitive restructuring reframing, behaviour modification, journal writing, time management, creative problem solving, and expressive art therapy, among others (Seaward, 2012). Secondary and tertiary prevention interventions could aim at strengthening mindfulness, resilience, and PWB. A randomised controlled trial in USA showed that the three-session resilience and coping intervention (RCI) was beneficial in increasing hope; and minimising depression and anxiety symptoms among undergraduate university students (Houston, First, Spialek,, Sorenson, Mills-Sandoval, Lockett et al., 2017). The RCI and other interventions might be adapted for use in higher education students in New Zealand.

Additional research is essential to further test the psychological well-being promotion model. The mechanisms (such as direct, mediating, and moderating effects) of internal and external RFP can be explored to fully understand variables in the model. Cross-cultural or cross-countries research are strongly encouraged to maximise generalisability of research findings. Prevention interventions (aiming to build resilience, mindfulness, and social support) could be developed for students. More research using quantitative (such as outcome evaluation) and qualitative methodology (such as process evaluation) can be carried out to test the effectiveness of the prevention interventions.

In summary, results from this study partially supported the psychological well-being model and highlighted the importance of resilience, mindfulness, and social support in the promotion of psychological well-being. Such information contributes to the current literature, inform prevention interventions and provide directions for future research.

\section{Conflicts of Interest}

The authors declare no conflicts of interest regarding the publication of this paper.

\section{References}

Adlaf, E. M., Gliksman, L., Demers, A., \& Newton-Taylor, B. (2001). The Prevalence of 
Elevated Psychological Distress amongst Canadian Undergraduates. Journal of American College Health, 50, 67-72. https://doi.org/10.1080/07448480109596009

Awang, M. M., Kutty, F. M., \& Ahmad, A. R. (2014). Perceived Social Support and Well-Being: First-Year Student Experience in University. International Education Studies, 7, 261-270. https://doi.org/10.5539/ies.v7n13p261

Bandura, A. (1977). Self-Efficacy: Towards a Unifying Theory of Behaviour Change. Psychological Review, 84, 191-215. https://doi.org/10.1037/0033-295X.84.2.191

Barbosa, P., Raymond, G., Zlotnick, C., Wilk, J., Toomey, R., \& Mitchell, J. (2013). Mindfulness-Based Stress Reduction Training Is Associated with Greater Empathy and Reduced Anxiety for Graduate Healthcare Students. Education for Health, 26, 9-14. https://doi.org/10.4103/1357-6283.112794

Beasley, M., Thompson, T., \& Davidson, J. (2003). Resilience in Response to Life Stress: The Effects of Coping and Cognitive Hardiness. Personality and Individual Differences, 34, 77-95. https://doi.org/10.1016/S0191-8869(02)00027-2

Bennett, S. (2002). Cultural Identity and Academic Achievement among Māori Undergraduate Nursing Students. In L. W. Nikora, M. Levy, B. Masters, W. Waitoki, N. Te Awekotuku, \& R. J. M. Etheredge (Eds.), The Proceedings of the National Mãori Graduates of Psychology Symposium 2002: Making a Difference. Hamilton: University of Waikato, 29-30 November 2002.

Benseman, J., Coxon, E., Anderson, H., \& Anae, M. (2006). Retaining Non-Traditional Students: Lessons Learnt from Pasifika Students in New Zealand. Higher Education Research \& Development, 25, 147-162. https://doi.org/10.1080/07294360600610388

Bishop, R., Berryman, M., Cavanagh, T., \& Teddy, L. (2009). Te Kohitanga: Addressing Educational Disparities Facing Māori Students in New Zealand. Teaching and Teacher Education, 25, 734-742. https://doi.org/10.1016/j.tate.2009.01.009

Blanco, C., Okuda, M., Wright, C., Hasin, D. S., Grant, B. F., Liu, S., \& Wolfson, M. (2008). Mental Health of College Students and Their Non-College Attending Peers. Archives of General Psychiatry, 65, 1429-1437. https://doi.org/10.1001/archpsyc.65.12.1429

Bland, J., \& Altman, D. (1997). Statistics Notes: Cronbach's Alpha. BMJ, 314, 572. https://doi.org/10.1136/bmj.314.7080.572

Bowlin, S. L., \& Baer, R. A. (2012). Relationships between Mindfulness, Self-Control, and Psychological Functioning. Personality and Individual Differences, 52, 411-415. https://doi.org/10.1016/j.paid.2011.10.050

Bowman, N. A. (2010). The Development of Psychological Well-Being among First-Ear College Students. Journal of College Student Development, 51, 180-200. https://doi.org/10.1353/csd.0.0118

Brown, K. W., \& Ryan, R. M. (2003). The Benefits of Being Present: Mindfulness and Its Role in Psychological Well-Being. Journal of Personality and Social Psychology, 84, 822-848. https://doi.org/10.1037/0022-3514.84.4.822

Browne, M. W., \& Cudeck, R. (1993). Alternative Ways of Assessing Model Fit. In K. A. Bollen \& J. S. Long (Eds.), Testing Structural Equation Models (pp. 136-162). Beverly Hills, CA: Sage.

Bryne, B. M. (2010). Structural Equation Modelling with AMOS: Basic Concepts, Applications, and Programming (2nd ed). New York: Routledge.

Campbell-Sills, L., \& Stein, M. B. (2007). Psychometric Analysis and Refinement of the Conor-Davidson Resilience Scale (CD-RISC): Validation of a 10-Item Measure of Resilience. Journal of Traumatic Stress, 20, 1019-1028. https://doi.org/10.1002/jts.20271 
Canty-Mitchell, J., \& Zimet, G. D. (2000). Psychometric Properties of the Multidimensional Scale of Perceived Social Support in Urban Adolescents. American Journal of Community Psychology, 28, 391-400. https://doi.org/10.1023/A:1005109522457

Cohen, S., Kamarck, T., \& Mermelstein, R. (1983). A Global Measure of Perceived Stress. Journal of Health and Social Behavior, 24, 386-396. https://doi.org/10.2307/2136404

Connor, K. M., \& Davidson, J. R. T. (2013). Development of a New Resilience Scale: The Connor-Davidson Resilience Scale (CD-RISC). Depression and Anxiety, 18, 76-82. https://doi.org/10.1002/da.10113

Cooke, R., Bewick, M. B., Barkham, M., Bradley, M., \& Audin, A. (2006). Measuring, Monitoring and Managing the Psychological Well-Being of First Year University Students. British Journal of Guidance \& Counselling, 34, 505-517. https://doi.org/10.1080/03069880600942624

Crudup, B. M. (2013). Stress, Social Support and Psychological Well-Being in College Students Attending Majority and Minority Institutions. Unpublished Master Thesis, University, MI: The University of Mississippi.

Daud, A., Klinteberg, B., \& Rydelius, P. A. (2008). Resilience and Vulnerability among Refugee Children of Traumatized and Non-Traumatized Parents. Child and Adolescent Psychiatry and Mental Health, 2, 7. https://doi.org/10.1186/1753-2000-2-7

Denovan, A., \& Macaskill, A. (2013). An Interpretative Phenomenological Analysis of Stress and Coping in First Year Undergraduates. British Educational Research Journal, 39, 1002-1024. https://doi.org/10.1002/berj.3019

DeVellis, R. (2003). Scale Development: Theory and Applications. Thousand Okas, CA: Sage.

Fava, G. A., \& Tomba, E. (2009). Increasing Psychological Well-Being and Resilience by Psychotherapeutic Methods. Journal of Personality, 77, 1903-1934. https://doi.org/10.1111/j.1467-6494.2009.00604.x

Feinstein, L., \& Hammond, C. (2004). The Contribution of Adult Learning to Health and Social Capital. Oxford Review of Education, 30, 199-221. https://doi.org/10.1080/0305498042000215520

Glaser, N., Hall, R., \& Halperin, S. (2006). Students Supporting Students: The Effects of Peer Mentoring on the Experiences of First Year University Students. Journal of the Australia and New Zealand Student Services Association, 27, 4-19.

Green, S. B. (1991). How Many Subjects Does It Take to Do a Regression Analysis? Multivariate Behavioral Research, 26, 499-510. https://doi.org/10.1207/s15327906mbr2603_7

Grove, S. K., Burns, N., \& Gray, J. R. (2013). The Practice of Nursing Research: Appraisal, Systhesis, and Generation of Evidence. St. Louis, MO: Elsevier \& Suanders.

Hair, J. G., Black, W. C. B., Babin, B. J., \& Anderson, R. E. (2010). Multivariate Data Analysis (7th ed.). Pearson Prentice Hall.

Houston, J. B. et al. (2017). Randomized Controlled Trial of the Resilience and Coping Intervention (RCI) with Undergraduate University Students. Journal of American College Health, 65, 1-9. https://doi.org/10.1080/07448481.2016.1227826

Hu, L., \& Bentler, P. M. (1999). Cut-Off Criteria for Fit Indexes in Covariance Structure Analysis: Conventional Criteria versus New Alternatives. Structural Equation Modelling: A Multidisciplinary Journal, 6, 1-55.

Kabat-Zinn, J. (1990). Full Catastrophe Living: Using the Wisdom of Your Body and Mind to Face Stress, Pain, and Illness. New York: Delacourt.

Keng, S. L., Smoski, M. J., \& Robins, C. J. (2011). Effects of Mindfulness on Psychological 
Health: A Review of Empirical Studies. Clinical Psychology Review, 31, 1041-1056. https://doi.org/10.1016/j.cpr.2011.04.006

Khan, A., \& Husan, A. (2010). Social Support as a Moderator of Positive Psychological Strengths and Subjective Well-Being. Psychological Reports, 106, 534-538. https://doi.org/10.2466/pr0.106.2.534-538

Klainin-Yobas, P., Ramirez, D., Fernandez, Z., Sarmiento, J., Thanoi, W., Ignacio, J., \& Lau, Y. (2015). Examining the Predicting Effect of Mindfulness on Psychological Well-Being among Undergraduate Students: A Structural Equation Modelling Approach. Personality and Individual Differences, 91, 63-68. https://doi.org/10.1016/j.paid.2015.11.034

Kypri, K., Langley, J. D., McGee, R., Saunders, J. B., \& Williams, S. (2002). High Prevalence, Persistent Hazardous Drinking among New Zealand Tertiary Students. Alcohol and Alcoholism, 37, 457-464. https://doi.org/10.1093/alcalc/37.5.457

Mak, W. W. S., Ng, I. S. W., \& Wong, C. C. Y. (2011). Resilience: Enhancing Well-Being through the Positive Cognitive Triad. Journal of Counseling Psychology, 58, 610-617. https://doi.org/10.1037/a0025195

Manthei, R. J., \& Gilmore, A. (2005). The Effect of Paid Employment on University Students Lives. Education \& Training, 47, 202-215.

https://doi.org/10.1108/00400910510592248

Nath, P., \& Pradhan, R. K. (2012). Influence of Positive Affect on Physical Health and Psychological Well-Being: Examining the Mediating Role of Psychological Resilience. Journal of Health Management, 14, 161-174. https://doi.org/10.1177/097206341201400206

Neuman, B., \& Fawcett, J. (2002). The Neuman Systems Model (4th ed.). Upper Saddle River, NJ: Prentice Hall.

Norman, G. R., \& Streiner, D. L. (2003). PDQ Statistics (3rd ed.). BC Decker.

Priesack, A., \& Alcock, J. (2015). Well-Being and Self-Efficacy in a Sample of Undergraduate Nurse Students: A Small Survey Study. Nurse Education Today, 35, e16-e20. https://doi.org/10.1016/j.nedt.2015.01.022

Rueger, S. Y., Malecki, C. K., \& Demaray, M. K. (2010). Relationship between Multiple Sources of Perceived Social Support and Psychological and Academic Adjustment in Early Adolescence: Comparisons across Gender. Journal of Youth and Adolescence, 39, 47-61. https://doi.org/10.1007/s10964-008-9368-6

Ryan, R. M., \& Deci, E. I. (2001). On Happiness and Human Potentials: A Review of Research on Hedonic and Eudaimonic Well-Being. In S. Fiske (Ed.), Annual Review of Psychology (pp. 141-166). Palo Alto, CA: Annual Reviews. https://doi.org/10.1146/annurev.psych.52.1.141

Ryff, C. D., \& Keyes, C. L. M. (1995). The Structure of Psychological Well-Being Revisited. Journal of Personality and Social Psychology, 69, 719-727. https://doi.org/10.1037/0022-3514.69.4.719

Salami, S. O. (2010). Emotional Intelligence, Self-Efficacy, Psychological Well-Being and Students' Attitudes: Implications for Higher Education. European Journal of Educational Studies, 2, 247-257.

Samaranayake, C., \& Fernando, A. T. (2011). Satisfaction with Life and Depression among Medical Students in Auckland, New Zealand. The New Zealand Medical Journal, 124.

Samaranayake, C., Arroll, B., \& Fernando, A. T. (2014). Sleep Disorders, Depression, Anxiety and Satisfication with Life among Young Adults: A Survey of University Stu- 
dents in Auckland, New Zealand. The New Zealand Medical Journal, 127.

Schwarzer, R., \& Jerusalem, M. (1995). Generalized Self-Efficacy Scale. In J. Weinman, S. Wright, \& M. Johnston (Eds.), Measures in Health Psychology: A User's Portfolio. Causal and Control Beliefs (pp. 35-37). Windsor: NFER-NELSON.

Seaward, B. L. (2012). Managing Stress: Principles and Strategies for Health and WellBeing (7th ed.). Burlington Jones \& Bartlett.

Seeds, P. M., Harkness, K. L., \& Quilty, L. C. (2010). Parental Maltreatment, Bullying, and Adolescent Depression: Evidence for the Mediating Role of Perceived Social Support. Journal of Clinical Child \& Adolescent Psychology, 39, 681-692. https://doi.org/10.1080/15374416.2010.501289

Seligman, M. E. P., \& Csikszentmihalyi, M. (2000). Positive Psychology: An Introduction. American Psychologist, 55, 5-14. https://doi.org/10.1037/0003-066X.55.1.5

Sheard, M. (2009). Hardiness Commitment, Gender, and Age Differentiate University Academic Performance. Educational Psychology, 79, 189-204.

Tamannaeifar, M. R., \& Motaghedifard, M. (2014). Subjective Well-Being and Its SubScales among Students: The Study of Role of Creativity and Self-Efficacy. Thinking Skills and Creativity, 12, 37-42. https://doi.org/10.1016/j.tsc.2013.12.003

Tassell, N. A., Flett, R. A., \& Gavala, J. R. (2010). Individualism/Collectivism and Academic Self-Enhancement in New Zealand Māori University Students. Journal of Pacific Rim Psychology, 4, 138-151. https://doi.org/10.1375/prp.4.2.138

Teh, C. H., Archer, J. A., Chang, W., \& Chen, S. A. (2013). Mental Well-Being Mediates the Relationships between Perceived Stress and Perceived Health. Stress and Health, 31, 71-77. https://doi.org/10.1002/smi.2510

Vaez, M., Kristenson, M., \& Laflamme, L. (2004). Perceived Quality of Life and Self-Rated Health among First-Year University Students. A Comparison with Their Same Age Working Peers. Social Indicators Research, 68, 221-234. https://doi.org/10.1023/B:SOCI.0000025594.76886.56

Vazquez, C., Hervas, G., Rahona, J. J., \& Gomez, D. (2009). Psychological Well-Being and Health. Contribution of Positive Psychology. Annuary of Clinical and Health Psychology, 5, 15-27.

Wagnild, G. M. (2009). A Review of the Resilience Scale. Journal of Nursing Measurement, 17, 105-113. https://doi.org/10.1891/1061-3749.17.2.105

Westen, D. (1999). Psychology: Mind, Brain, and Culture (2nd ed.). New York: Wiley.

Zhong, L. F. (2009). Academic Stress and Subjective Well-Being: The Moderating Effects of Perceived Social Support. In Proceeding at 16th International Conference on Industrial Engineering and Engineering Management (1321-1324). Piscataway, NJ: Institute of Electrical and Electronics Engineers. https://doi.org/10.1109/ICIEEM.2009.5344424

Zimet, G. D., Dahlem, N. W., Zimet, S. G., \& Farley, G. K. (1988). The Multidimensional Scale of Perceived Social Support. Journal of Personality Assessment, 52, 30-41. https://doi.org/10.1207/s15327752jpa5201_2 